\title{
Colletotrichum trifolii Mutants Disrupted in the Catalytic Subunit of cAMP-Dependent Protein Kinase Are Nonpathogenic
}

\author{
Zhonghui Yang and Martin B Dickman \\ Department of Plant Pathology, University of Nebraska Lincoln, Lincoln 68583-0722, U.S.A. \\ Accepted 29 January 1999.
}

Colletotrichum trifolii is the fungal pathogen of alfalfa that causes anthracnose disease. For successful plant infection, this fungus must undergo a series of morphological transitions following conidial attachment, including germination and subsequent differentiation, resulting in appressorium formation. Our previous studies with pharmacological effectors of signaling pathways have suggested the involvement of cyclic AMP (cAMP)-dependent protein kinase (PKA) during these processes. To more precisely evaluate the role of PKA in $C$. trifolii morphogenesis, the gene encoding the catalytic (C) subunit of PKA (Ct-PKAC) was isolated, sequenced, and inactivated by gene replacement. Southern blot analysis with $C$. trifolii genomic DNA suggested that $C t$-PKAC is a single-copy gene. Northern (RNA) blot analysis with total RNA from different fungal growth stages indicated that the expression of this gene was developmentally regulated. When $C t-P K A C$ was insertionally inactivated by gene replacement, the transformants showed a small reduction in growth relative to the wild type and conidiation patterns were altered. Importantly, PKA-deficient strains were unable to infect intact alfalfa (host) plants, though only a slight delay was observed in the timing for conidial germination and appressorial formation in the Ct-PKAC disruption mutants. Moreover, these mutants were able to colonize host tissues following artificial wounding, resulting in typical anthracnose disease lesions. Coupled with microscopy, these data suggest that the defect in pathogenicity is likely due to a failure in penetration. Our results demonstrate that PKA has an important role in regulating the transition between vegetative growth and conidiation, and is essential for pathogenic development in $C$. trifolii.

Colletotrichum trifolii is the fungal pathogen that causes alfalfa anthracnose (Barnes et al. 1969), which is one of the most economically important fungal diseases of alfalfa, particularly in hot and humid areas (Churchill et al. 1988). $C$. trifolii attacks leaves, stems, and crowns of susceptible alfalfa cultivars. Microscopic examination of diseased tissue reveals abundant mycelial growth and the production of acervuli, which are conidia-bearing structures formed on the surface of

Corresponding author: Martin B. Dickman; Telephone: 1-402-472-2849; Fax: 1-402-472-2853; E-mail: mbd@unlinfo.unl.edu the lesions. When ruptured, they serve as a source of secondary inoculum. Alfalfa anthracnose has traditionally been controlled through breeding for resistant cultivars, but this time-consuming process has been found to be problematic, since new virulent strains have been observed following development of "resistant" varieties. Thus, alternative strategies are needed to improve alfalfa yield (Ostazeski et al. 1979).

Pathogenicity of $C$. trifolii depends on cellular differentiation, which is initiated by deposition and attachment of conidia on host surfaces, followed by conidial germination, germ tube elongation, and appressorial formation (Dickman 1988; Dickman et al. 1995). For Colletotrichum spp. and some other appressoria-forming fungi, proper appressorium development is necessary for successful infection (Kubo et al. 1981; Wolkow et al. 1983; Perpetua et al. 1994). However, the environmental cues that trigger these pre-penetration events and the responsive biochemical pathways that mediate these transitions are poorly understood. Thus, the isolation and characterization of molecules involved in these processes will improve our understanding of disease development and should identify targets for design of new control strategies (Dickman et al. 1995).

In fungi as well as other eukaryotes, cell growth and differentiation are regulated through the activation of intracellular signal transduction pathways in response to external stimuli. Protein phosphorylation/dephosphorylation has been shown to be important for regulation of these pathways (Johnson et al. 1996). Cyclic AMP (cAMP)-dependent protein kinase (PKA) was one of the first protein kinases to be purified (Walsh et al. 1968), and the gene encoding the catalytic subunit of PKA was also the first to be sequenced. PKA was also the first protein kinase for which a crystal structure was determined (Shoji et al. 1983; Knighton et al. 1991). PKA has been found in all eukaryotes studied and is the main (if not the only) receptor for cAMP, the first documented second messenger (Taylor et al. 1990). With the exception of PKA in Dictyostelium discoideum, PKA is a tetrameric protein, consisting of two catalytic (C) and two regulatory (R) subunits in the inactive holoenzyme. After binding of cAMP to the $\mathrm{R}$ subunits, the conformation of the holoenzyme changes, resulting in the release of the two active C subunits (Taylor et al. 1990). While numerous studies have investigated the wide range of PKA function in mammals and yeasts, it is only recently that PKA has been identified and functionally analyzed in phytopathogenic fungi (Kronstad 1997). In the rice blast pathogen 
Magnaporthe grisea, PKA was found to be necessary for successful penetration, as PKA C subunit disruption mutants were delayed in appressoria development and were unable to colonize intact plants (Mitchell and Dean 1995; Xu et al. 1997). In Ustilago maydis, the causal agent of corn smut, fungal dimorphism was altered in adenylate cyclase mutants, while mutants defective in the $\mathrm{R}$ subunit of PKA failed to form symptomatic galls on host plants and were defective in cytokinesis (Gold et al. 1994, 1997). Our previous studies with pharmacological effectors in signal transduction have suggested that PKA is involved in pre-penetration morphogenesis in C. trifolii (Yang and Dickman 1997). In order to analyze the function of PKA directly, we have isolated, cloned, and characterized the $\mathrm{C}$ subunit gene of PKA. When the gene for the PKA C subunit was inactivated by gene replacement, the transformants grew more slowly, conidiated profusely, and were nonpathogenic.

\section{RESULTS}

\section{Isolation and sequence of Ct-PKAC.}

Three degenerate primers were designed based on the conserved regions of other PKA C subunits (Hanks and Quinn 1991). Primer pair 1 and 2 yielded a single polymerase chain reaction (PCR) fragment of about $200 \mathrm{bp}$. The sequence of this fragment indicated high homology with the protein kinase $\mathrm{C}$ family members; therefore, this fragment was not used further for this work (data not shown). Primer pair 1 and 3 yielded a single PCR fragment of approximately $100 \mathrm{bp}$, and the DNA sequence of this PCR fragment indicated high homology with other PKA $C$ subunit genes. When a $C$. trifolii cDNA library was screened with this fragment as a probe, two distinct groups of positive phage clones were found. One had inserts of around $2.5 \mathrm{~kb}$ and the other had inserts of around 0.9 $\mathrm{kb}$. Both inserts were subcloned and completely sequenced on both strands. An open reading frame of 1,620 bp (540 amino acids) was predicted from the large fragment $(2,509 \mathrm{bp})$. The deduced amino acid sequence shared high homology with the $\mathrm{C}$ subunit of PKA in other fungi, which is shown in Figure 1, and the predicted protein was named Ct-PKAC. The most striking feature of this peptide is the presence of 26 consecutive glutamine residues from amino acids 161 to 186 . The sequence of the smaller insert revealed a truncated fragment of $C t-P K A C$ cDNA from 436 to 1342 relative to the full-length fragment. When $C$. trifolii genomic DNA was digested with BamHI, EcoRI, HindIII, and PstI, and probed with either the PCR fragment or the truncated cDNA fragment, single bands $(1.4,10,4$, and $1.3 \mathrm{~kb}$, respectively) were found in all of the four digests under both low and high stringency conditions, suggesting that this gene was present in a single copy, and that there are no highly related copies of this gene in $C$. trifolii.

\section{Ct-PKAC expression is developmentally regulated.}

To examine $C t-P K A C$ expression, total RNA was isolated from four defined fungal growth stages during $C$. trifolii development. Mycelia and conidia were obtained from YPSS liquid culture. Conidia were washed twice in sterile, deionized, distilled water prior to further treatment. For the generation of germinated conidia and appressoria, washed conidia were resuspended in distilled water and put into glass petri dishes (Yang and Dickman 1997). Germinated conidia were harvested after $2 \mathrm{~h}$, while mature appressoria were harvested after overnight incubation. In addition, a time course of $C t$ $P K A C$ expression was done by isolating RNA from germinating conidia at hourly intervals following the induction of germination. Northern (RNA) blot analyses were performed with the full-length cDNA of $C t-P K A C$ as a probe. The highest level of expression of $C t-P K A C$ was found in the conidial stage, with slightly lower levels of $C t-P K A C$ transcript in mature appressoria (Fig. 2A). PKA expression during in vitro morphogenesis oscillated (Fig. 2B). One hour following the induction of germination, Ct-PKAC transcript levels were reduced; however, when appressorial development was initiated 2 to $3 \mathrm{~h}$ after induction on hard surfaces, $C t-P K A C$ transcript levels increased, and then decreased as appressoria matured. Only basal expression levels were found in vegetatively grown mycelia. The presence of the higher molecular weight band relative to the major band in both Figure $2 \mathrm{~A}$ and $\mathrm{B}$ may indicate non-processed RNA of the $C t-P K A C$ transcript. Each of these expression studies was performed twice with similar results.

\section{Phenotypic characterization of $C t-P K A C$ disruption mutants.}

DNA-mediated gene replacement was performed to evaluate the role of PKA in $C$. trifolii with the DNA construct shown in Figure 3. Three mutants containing the disrupted $C t$ $P K A C$ gene were obtained from a total of 150 hygromycin $\mathrm{B}$ resistant transformants and gene disruption was confirmed by Southern blot analysis (Fig. 4). The 1.4-kb BamHI fragment representing the endogenous copy of $C t-P K A C$ was absent in these transformants, and instead two fragments (2.3 and 1.1 $\mathrm{kb}$ ) representing the disrupted copy of the gene were present (the hygromycin phosphotransferase $[h p h]$ gene cassette contains a BamHI site). The second fragment of $1.1 \mathrm{~kb}$ in M3 might be due to an independent ectopic integration event in the same transformant. The inactivation of Ct-PKAC expression was confirmed by Northern blot analysis with total RNA obtained from conidia and mycelia grown in liquid culture (data not shown). Furthermore, the loss of PKA activity in the disruption mutants was tested by measuring PKA enzymatic levels in the wild-type strain and one selected PKA disruption mutant, M8. In the conidial stage, PKA activity levels in the wild-type strain were $36.96 \pm 6.28(\mathrm{pmol} / \mathrm{min} / \mu \mathrm{g}$ of total protein); in M8, PKA activity levels were $0.05 \pm 0.03$ ( $\mathrm{pmol} / \mathrm{min} /$ $\mu \mathrm{g}$ of total protein). These numerical values were based upon three individual assays with a minimum of three replications in each assay.

PKA replacement mutants showed some reduction in growth relative to the wild-type strain. On YPSS agar, the wild-type strain grew on average $2.8 \pm 0.7 \mathrm{~mm}$ per day, while the mutants grew at $1.9 \pm 0.2 \mathrm{~mm}$ per day. On minimal agar medium, the wild-type strain grew $2.4 \pm 0.4 \mathrm{~mm}$ per day, and the mutants $1.8 \pm 0.2 \mathrm{~mm}$ per day (the growth rate of the three mutants was identical on both media, and the results were the average of the three mutants). $C t-P K A C$ disruptants were also affected in conidiation. On YPSS agar plates, conidiation in the wild-type strain was only observed in the center of each colony, as evidenced by the characteristic salmon color; in the PKA disruption mutants, conidiating mycelia were readily observed at the edge of the colonies under a light microscope as the mutants conidiated at hyphal tips during elongation and 
Ctrifol11

Mgrisea

Spombe

Umaydis

Ctrifol11

Mgrisea

Spombe

Umaydis
$.10 \cdot .0 .20 \cdot 0.00 .000 .000$

1 : MPTLGFLKKKRTREGNQDPQGSLPTSPVTPTSSKPFDSSISTTLS磁SNNSQATSQPSGP : 60 1 : MP SLGFLKKKRTRDGNND. NSSQPASPVTPTAAQSFEQAQVLGAP俉A INNSHAHTQQQSY: 59 1: $\sim \sim \sim \sim \sim \sim \sim \sim \sim \sim \sim \sim \sim \sim \sim \sim \sim \sim \sim \sim \sim \sim \sim \sim$ MDTTAVASKGSTNVGSSTD簑LSTSASLHPSMNAG: 34

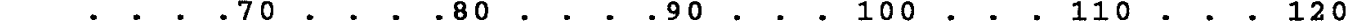

61 : GQKQQEDPASSEA. AKNQQMYPVT . . . . . VHPA PNQQHYNQQGEPQQN"筑P. S

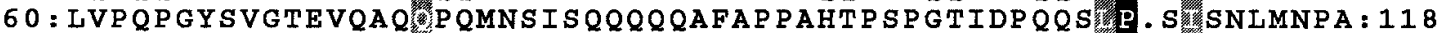

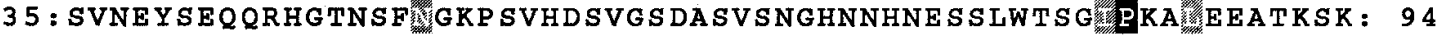

. . 130 . . . 140 . . 150 . . . 160... $170 . . .180$

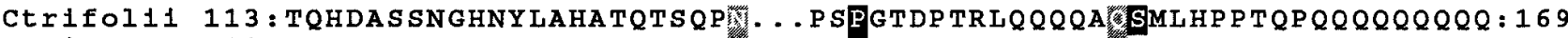
Mgrisea Spombe 119 : VQQQNSQP SANFQPQSQSQSQS4S $Q F P L P P S H G N G D Q S Q Q Q$ WFQVQQQIQSQQDAMDIQP: 178 95 : KPDSLVST ST SGCASAHSVGYQNIDNLIPSP LPESASRSSS Umaydis

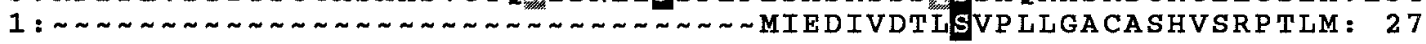

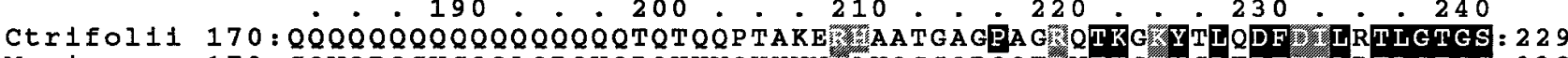
Mgrisea Spombe Umaydis

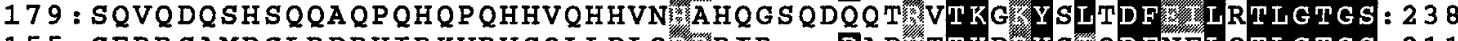

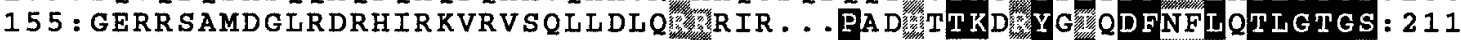

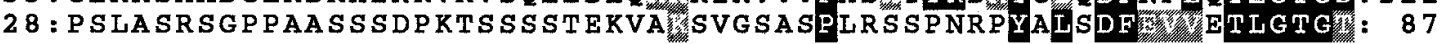

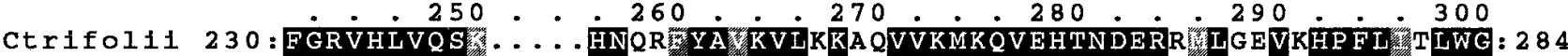
Mgrisea Spombe Umaydis

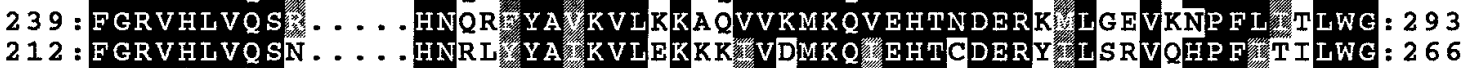

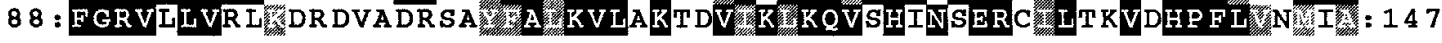

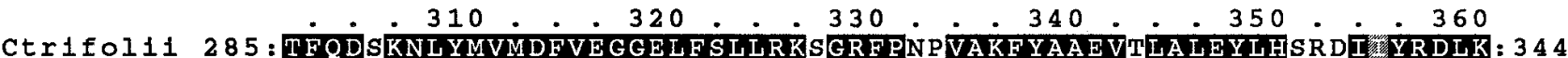
Mgrisea spombe

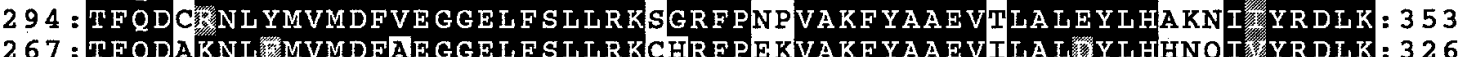
Umaydis 148 : FQDSKNCYMUM

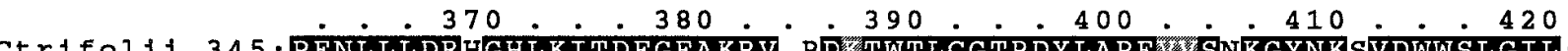

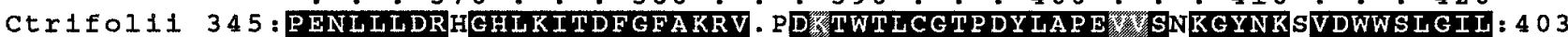
Mgrisea spombe

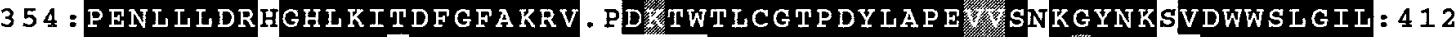
Umaydis 327 : PENLLLDRFGHLKIVDFGFAKRVST SNCCTLCGTPDYLAPE. USLKWYNKAADWWSLGIL: 386

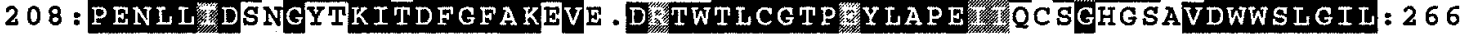

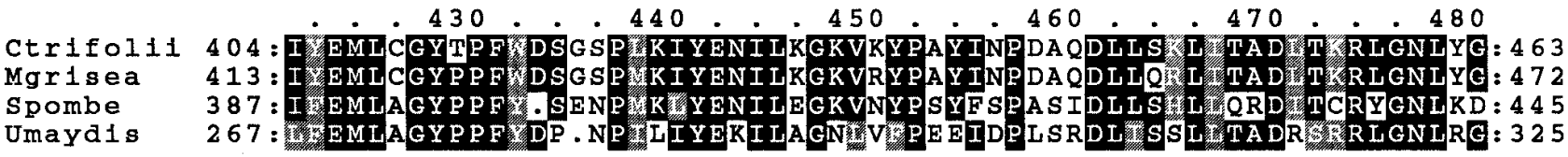

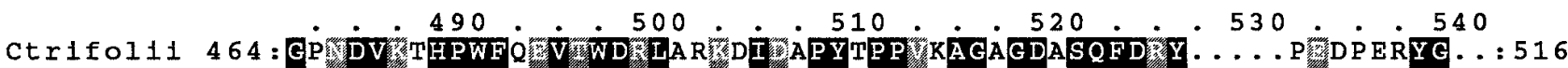
Mgrisea spombe 473 : GSSDV W Umaydis

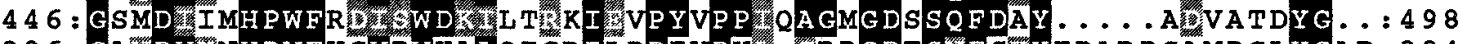
326 : GAMDV

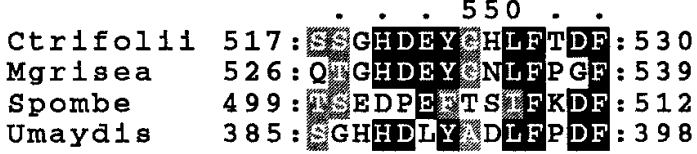

Fig. 1. Alignment of the Ct-PKAC predicted amino acid sequence with those of cyclic AMP (cAMP)-dependent protein kinase (PKA) catalytic subunit sequences from selected fungi. Alignment was created with the PILEUP program in GCG and presented with the BOXSHADE program. Residues identical in at least three sequences are indicated by black boxes; similar residues are indicated by gray boxes. GenBank accession numbers for the nucleotide sequences of those genes are as follows: Colletotrichum trifolii, AF046921; Magnaporthe grisea, U12335; Schizosaccharomyces pombe, D23667; Ustilago maydis, AF025290. 
branching. However, the total amounts of conidiation in YPSS agar medium, comparing the wild-type strain and the mutants, were similar (data not shown). The timing of conidiation also differed between the wild type and the PKA mutants. In YPSS, MM, and water agar media, the mutants all conidiated 3 to 4 days earlier than the wild type; in liquid culture, the mutants conidiated 1 to 2 days later than the wild type did, but conidiation lasted up to 10 days, while the wild type conidiated only 3 to 4 days. These observations were consistent in three separate experiments. Addition of cAMP to $10 \mathrm{mM}$ in the media failed to restore phenotypic changes in these disruptants (data not shown). When the mutants were tested for appressorial formation on glass slides, the percentage of appressorial formation and the morphology of the mature appressoria were indistinguishable between the mutants and the wild-type strain, with less than 1-h delay in conidial germination and subsequent appressorial formation in the mutants. In all parameters

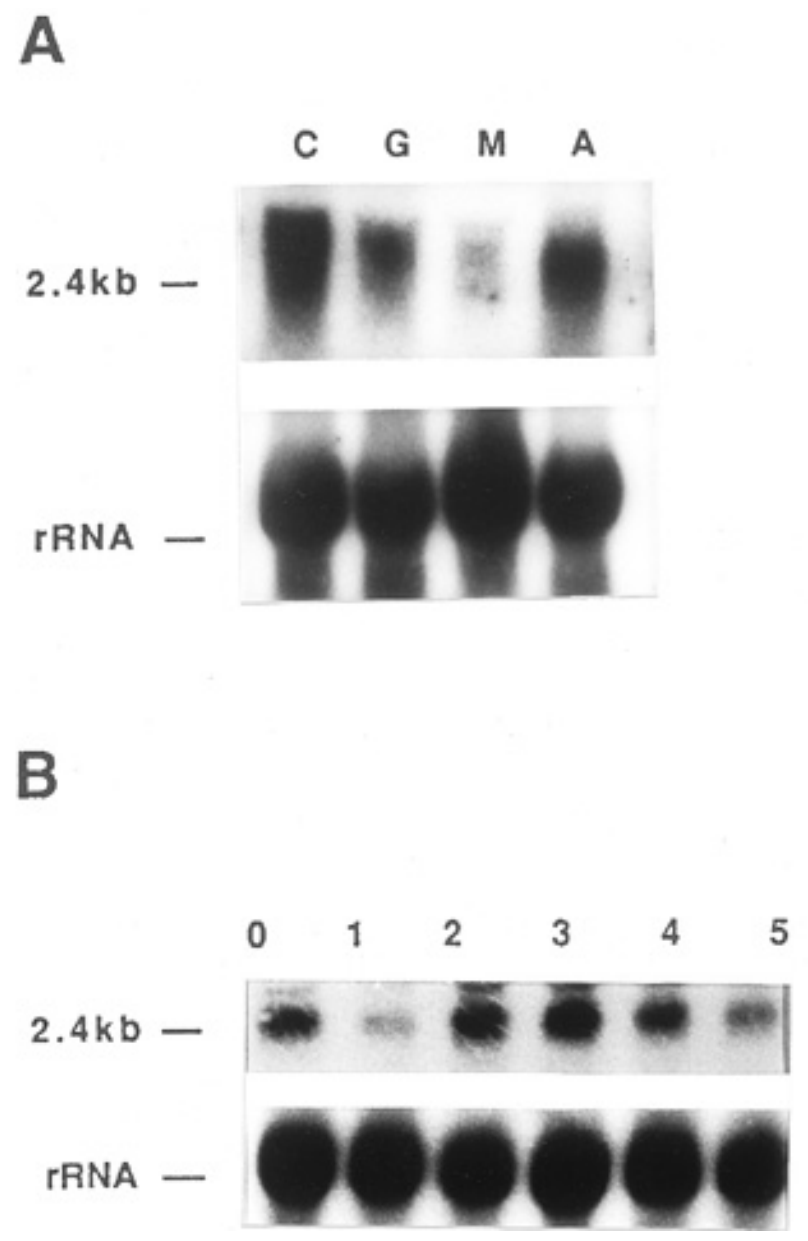

Fig. 2. Northern (RNA) blot analyses of $C t-P K A C$ expression. A, C, conidia; G, germinating conidia; M, mycelia; A, mature appressoria. Washed conidia before induction of germination were used as the zero time point sample. The membrane was probed with the full-length ${ }^{32} \mathrm{P}-$ labeled cDNA. Hybridization and washing were performed under high stringency conditions. After autoradiography, the blot was then reprobed with rDNA from Colletotrichum gloeosporioides (Stephensen et al. 1997). B, Ct-PKAC expression during conidial germination at 1-h intervals from 0 to $5 \mathrm{~h}$ after induction of germination. Total RNA was isolated in TriZol solution and separated by $1 \%$ agarose gel in $1 \times$ morpholinepropanesulfonic acid (MOPS)/formaldehyde running buffer (15 $\mu \mathrm{g}$ of total RNA per lane was loaded). evaluated, the three disruption mutants were indistinguishable from each other. Taken together, these observations suggested that PKA is required for normal vegetative growth and conidiation, but not for appressorial formation in C. trifolii.

\section{Ct-PKAC is required for pathogenicity in C. trifolii.}

Pathogenicity of the mutants was tested by inoculation onto detached leaves from 1-month-old alfalfa. On detached leaves, $48 \mathrm{~h}$ after inoculation, no obvious morphological differences were observed in the germinated conidia and appressoria formed by the wild-type strain and the mutants, and also there were negligible differences between the wild type and the mutants with respect to the percentage of appressoria formation (over $90 \%$ of inoculated conidia formed appressoria in

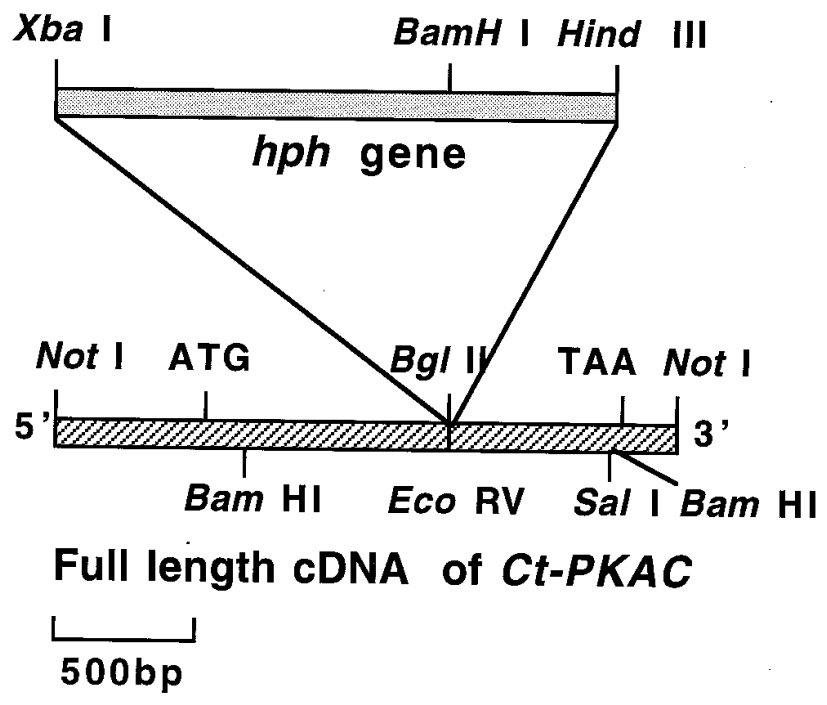

Fig. 3. Construction of the Ct-PKAC gene replacement vector. The fulllength cDNA of Ct-PKAC was cloned into the NotI site of the pBluescriptKS plasmid. The start and stop codons of the Ct-PKAC open reading frame are indicated. Hygromycin phophotransferase $(h p h)$ gene expression cassette was released from plasmid pHA1.3 (Powell and Kistler 1990) by HindIII and XbaI, blunt ended, and inserted into the BgIII site of $C t-P K A C$. The fragment containing the gene-replacement construct was later separated by NotI from the pBluescript vector, purified by gelelectrophoresis, and used to transform Colletotrichum trifolii protoplasts.

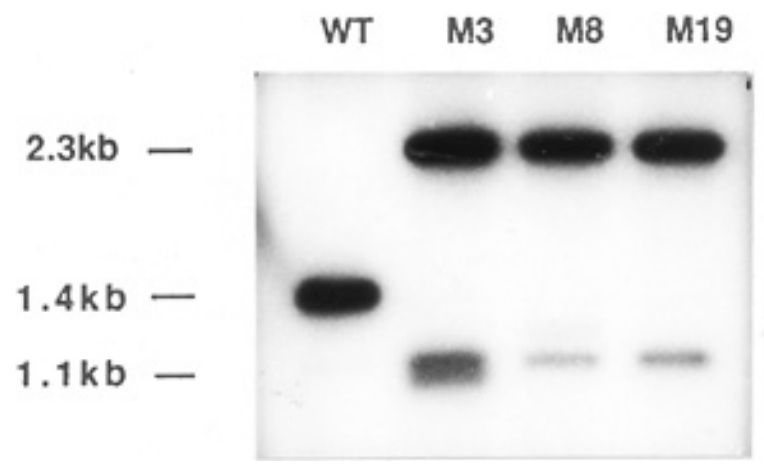

Fig. 4. Southern blot analysis of the wild-type strain and the three CtPKAC disruption mutants. Genomic DNA was isolated as described (Panaccione et al. 1988). DNA from each strain ( $2 \mu \mathrm{g}$ per lane) was digested with BamHI, separated on $0.8 \%$ agarose gel, transferred to a nylon membrane, and hybridized with the truncated cDNA fragment of $C t$ $P K A C$. Hybridization and washing were performed under high stringency conditions. 
both the wild-type strain and the mutants). Nearly all the inoculated conidia germinated and formed appressoria (Fig. 5A and B). However, at $96 \mathrm{~h}$ post inoculation, abundant mycelia were observed only in the wild-type-inoculated detached leaves; little vegetative growth was observed in the mutantinoculated leaves. At 5 days post inoculation, lesions and acervuli were observed on detached leaves inoculated with the wild-type strain, but no lesions were observed in detached leaves inoculated with the mutants (Figs. 5C,D and 6). Similar results were obtained when the whole plants instead of the detached leaves were inoculated (data not shown). To determine whether the loss of pathogenicity was due to a failure in penetration, detached alfalfa leaves were wounded prior to inoculation. As shown in Figure 6, at 5 days post inoculation, lesions were observed in leaves inoculated with either the wild-type strain or the mutants, and acervuli were found in these lesions. Moreover, conidia recovered from the lesions remained hygromycin B resistant, and PCR analysis confirmed the replacement genotype (data not shown).

\section{DISCUSSION}

Isolation and molecular cloning of $C t-P K A C$.

The $\mathrm{C}$ subunit gene of PKA was isolated and cloned from C. trifolii. The sequence of the deduced protein was similar to that of other PKA C subunits, with highest homology between deduced Ct-PKAC protein and the $\mathrm{C}$ subunits of PKA in other fungi (Toda et al. 1987; Maeda et al. 1994; Oliveira et al. 1994; Mitchell and Dean 1995). From the overall sequence of the predicted Ct-PKAC protein, the $\mathrm{N}$ terminus represented the most diverged region when the $\mathrm{C}$ subunits were compared with their counterparts (Fig. 1). This divergence may be involved in the specific functions of these proteins in their respective organisms. An interesting feature of Ct-PKAC protein was the presence of 26 consecutive glutamine residues near its $\mathrm{N}$ terminus. Other fungal serine/threonine kinases that contain glutamine-rich regions are the $\mathrm{C}$ subunit of PKA in $M$. grisea (Mitchell and Dean 1995) and TB3 in C. trifolii, which is highly expressed during conidial germination and hyphal elongation (Buhr et al. 1996). Homopolymeric tracts of glutamine are not uncommon and have been found in a number of mammalian transcription factors (Emili et al. 1994; Gerber et al. 1994; Tanaka et al. 1994). Glutamine-rich regions are known to be important in protein-protein interactions, and have been found in proteins that activate transcription (Gerber et al. 1994; Tanaka et al. 1994). Thus, the possibility exists that the $\mathrm{C}$ subunit functions in the nucleus. Antibodies against the $\mathrm{C}$ subunit are being generated that will be used for localization of this protein.

Southern hybridization indicated that $C t-P K A C$ is a singlecopy gene, as has been reported in several other fungi (Oliveira et al. 1994; Maeda et al. 1994; Mitchell and Dean 1995; Bencina et al. 1997), and this is consistent with the total loss of PKA activity when targeted disruption was performed. This is also supported by the observation that addition of cAMP in the media could not restore phenotypic changes in those PKA disruptants.

\section{Ct-PKAC expression during $C$. trifolii development.}

Our previous data have suggested the involvement of cAMP/PKA in pre-penetration development in $C$. trifolii
(Yang and Dickman 1997). The expression patterns of $C t$ $P K A C$ were consistent with these observations. As shown in Figure $2 \mathrm{~A}$ and $\mathrm{B}, C t-P K A C$ expression was regulated during morphogenesis with transcript levels oscillating during conidial germination and in four distinct growth stages. Higher levels of the Ct-PKAC transcript were found in the conidial stage and in mature appressoria, as well as at the onset of appressorial formation. Developmental regulation of expression of the $\mathrm{C}$ subunit gene has been observed in Blastocladiella emersonii, and coordinate regulation of gene expression at the transcriptional level of both the $\mathrm{C}$ and $\mathrm{R}$ subunits of PKA has been reported in this organism, with high levels of expression of both subunits observed during the developmental transition between zoospore formation and early germination (Marques et al. 1992; Oliveira et al. 1997). In other organisms, the expression of PKA genes has also been found to be developmentally regulated, although translational and posttranslational modes of regulation have also been described (Showers and Maurer 1986; Uhler et al. 1986; Gross et al. 1990; Lu et al. 1990).

\section{$C t-P K A C$ is required for normal growth and conidiation in $C$. trifolii.}

The $C$. trifolii PKA C subunit gene was insertionally inactivated by homologous recombination. Genotypes were confirmed by Southern blot analysis. Importantly, Ct-PKAC transcripts were absent in these mutants. Further, when PKA enzymatic levels of the wild-type isolate and one selected PKA disruptant were measured, negligible activity was detected in the PKA disruptant. Growth rate comparisons showed that the three PKA C mutants were considerably retarded in growth regardless of nutritional conditions but that the timing of conidial germination and initiation of appressorial development were similar to those of the wild type. These observations are in contrast to studies in the rice blast pathogen $M$. grisea, where the PKA C subunit disruption mutants showed a pronounced delay in appressoria development (Mitchell and Dean 1995; Xu et al. 1997). PKA regulation of growth rate has been observed in other organisms as well. In both budding yeast and fission yeast, loss of PKA resulted in delay of spore germination, and our data are consistent with the growth retardation observed in the PKA-deficient mutants of yeasts (Toda et al. 1987; Maeda et al. 1994), which may be attributed to altered mobilization of carbohydrate reserves.

In fungi, PKA has been shown to be involved in the transition from vegetative to reproductive growth. For example, PKA mutants in both budding and fission yeasts sporulated constitutively in the absence of a nutrient-starvation signal that is normally required for wild-type strains to enter meiosis (Maeda et al. 1994 ). Induced PKA activity resulted in sterility (Toda et al. 1987; Jin et al. 1995). Consistent with these data, in Neurospora crassa the "crispy" mutants with defective adenylate cyclase not only grew slowly but also sporulated more profusely in solid media (Terenzi et al. 1976). Mutants of $U$. maydis deficient in the R subunit gene of PKA colonized the host plant (maize) normally, but failed to produce galls (Gold et al. 1997). Additional examples are provided by studies of mutants defective in PKA upstream regulators. For example, loss of sporulation was observed when the Gi $\alpha$ subunit was disrupted in Cryphonectria parasitica, resulting in higher levels of cAMP in these strains (Gao and Nuss 1996). In As- 

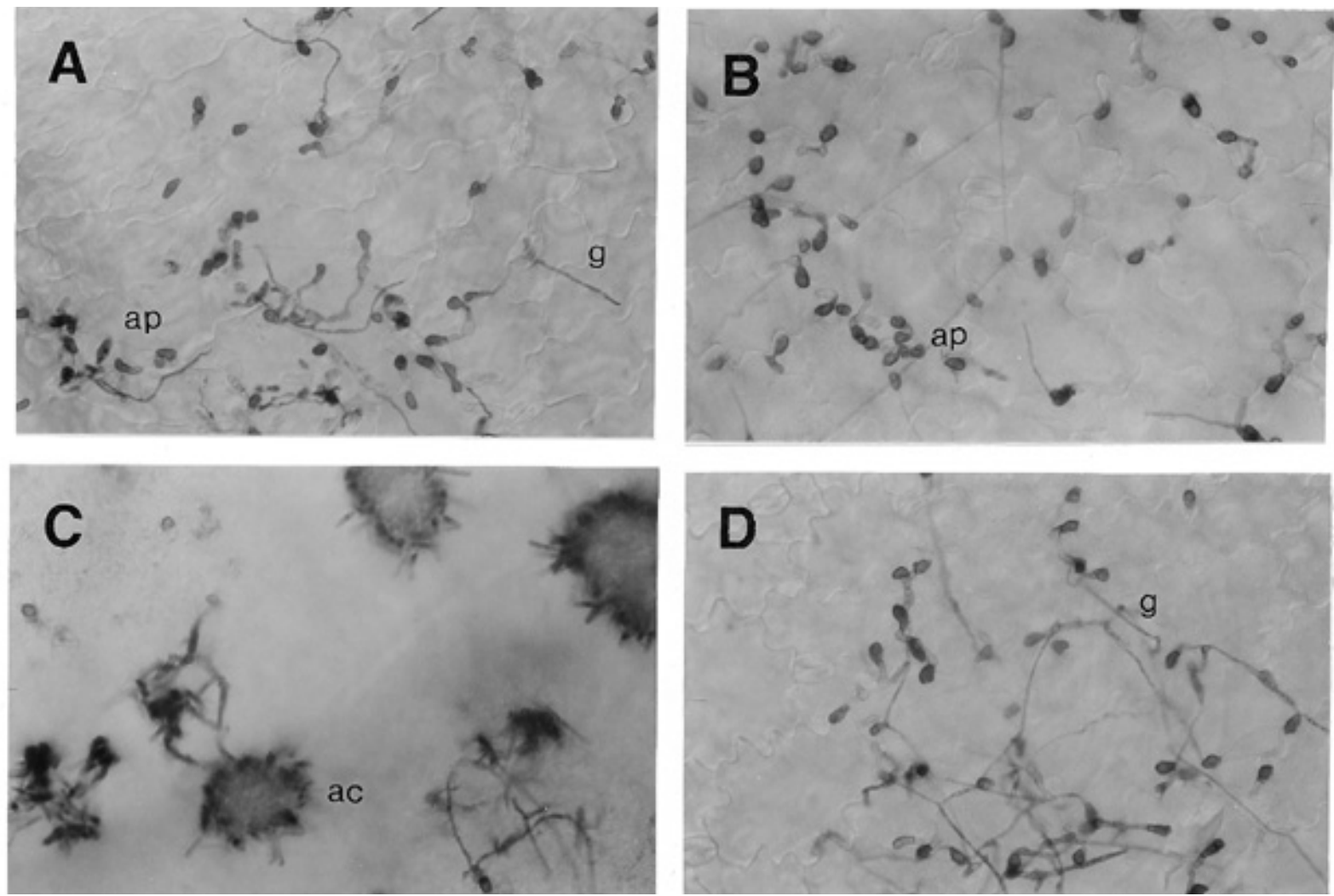

Fig. 5. Microscopic examination of fungal development on susceptible alfalfa leaves in the wild-type strain and one of the disruption mutants, M8. Conidia from both strains were obtained from YPSS liquid culture, washed, and diluted to $5 \times 10^{5}$ conidia per ml. After the addition of $0.1 \%$ Tween 20 to the conidia suspension, droplets $(2 \mu \mathrm{l})$ were inoculated onto detached leaves from 1-month-old plants. Inoculated leaves were incubated in $100 \%$ humidity at ambient temperature. After $48 \mathrm{~h}$, and 5 days, the inoculated leaves were cleared in a solution containing equal volumes of $95 \%$ ethanol and $100 \%$ acetic acid. The fungal tissues were stained with Trypan blue. $\times 400$ magnification. A and C, Wild-type strain inoculated leaves. B and D, M8 inoculated leaves. $\mathbf{A}$ and $\mathbf{B}, 48 \mathrm{~h}$ after inoculation. $\mathbf{C}$ and $\mathbf{D}, 5$ days after inoculation. ap: appressoria; g: germ tubes; ac: acervuli.

1

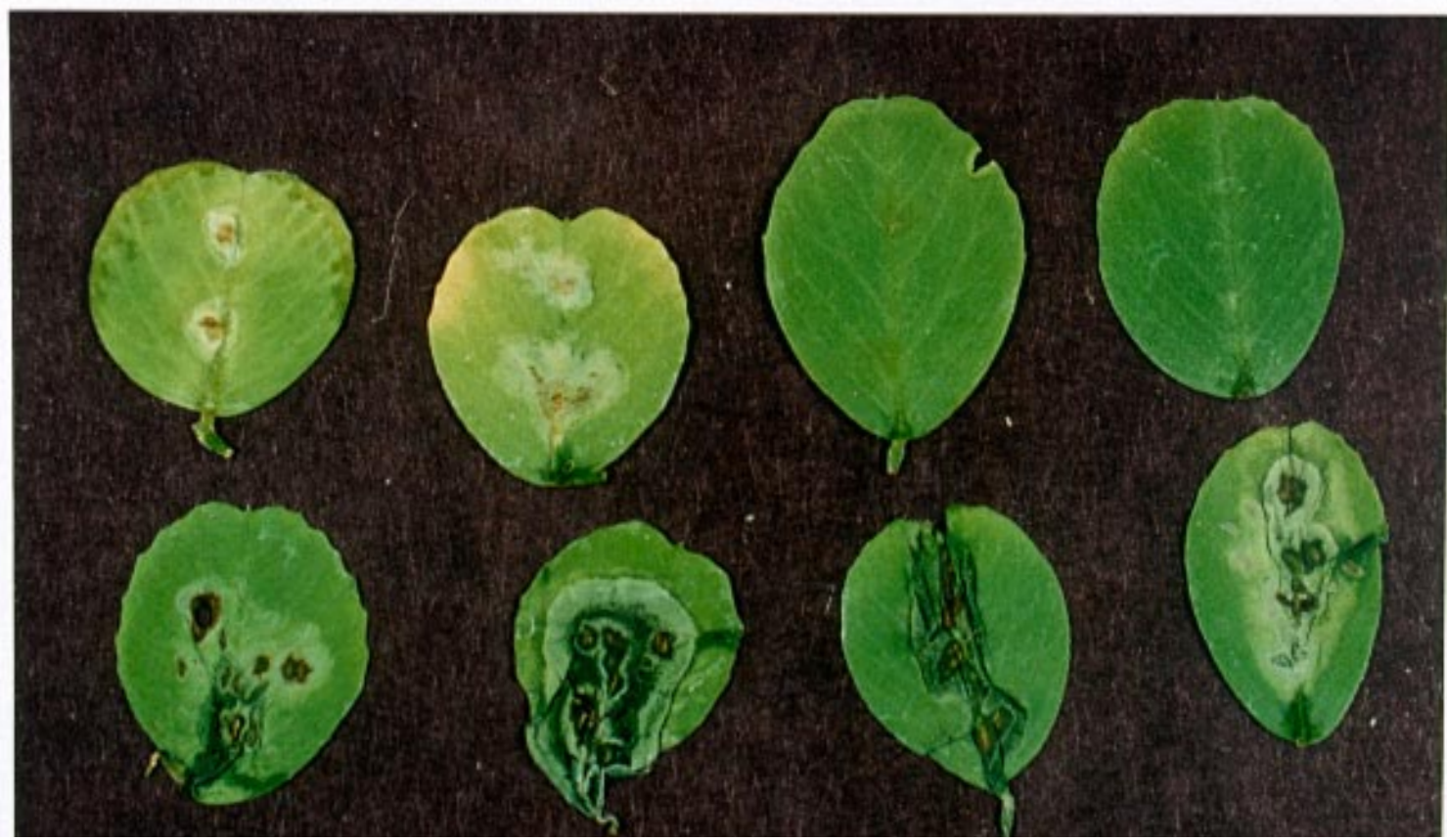

Fig. 6. Inoculation of nonwounded and wounded, susceptible alfalfa leaves by the wild-type strain and the cyclic AMP (cAMP)-dependent protein kinase (PKA) disruption mutant M8. Detached alfalfa leaves from 1-month-old plants were wounded by pinching with blunt-ended forceps. Leaves (wounded and nonwounded) were inoculated and incubated as described in Figure 5. The picture was taken 5 days after inoculation. Lanes 1 and 2: leaves inoculated with the wild-type strain; lanes 3 and 4: leaves inoculated with mutant M8. 
pergillus nidulans, sporulation patterns were altered in a $\mathrm{G} \alpha$ subunit mutant as well as in a RGS (regulator of $\underline{G}$ protein signaling) mutant (Lee and Adams 1996; Yu et al. 1996; Hicks et al. 1997). The changes in the conidiation pattern of $C$. trifolii PKA disruption mutants are in accordance with these observations. In $S$. cerevisiae, PKA affects cell division by directly regulating the expression of G1 cyclins (Baroni et al. 1994; Tokiwa et al. 1994).

\section{Loss of pathogenicity in Ct-PKAC disruption mutants.}

The most significant change in these PKA replacement strains was that the mutants could not infect intact, susceptible host plants. Disruptants inoculated onto either detached leaves or entire plants germinated and formed appressoria in a manner similar to that of the wild type. After $48 \mathrm{~h}$ of inoculation, a period preceding host penetration, no obvious differences were observed between the wild type and the PKA-deficient mutants. Conidia from both strains germinated and formed appressoria after $48 \mathrm{~h}$. The slight difference in hyphal growth between Figure 5A and B was consistent with the retarded growth in the mutants. Differences were initially observed 72 to $96 \mathrm{~h}$ post inoculation. Microscopic studies have shown that successful penetration by $C$. trifolii was completed by $72 \mathrm{~h}$ post inoculation (Mould et al. 1991a, 1991b; Z. Yang and M. B. Dickman, unpublished data). After 5 days, lesions were present in wild-type-inoculated leaves. Acervuli and abundant mycelial growth were observed in these lesions, whereas in the PKA-deficient, mutant-inoculated leaves, no lesions were present and little mycelial mass was observed. However, characteristic lesions and acervuli were found when leaves were wounded prior to inoculation either with the wild-type strain or the mutants. The fact that these PKA-deficient mutants could form appressoria, colonize wounded leaves, and produce acervuli suggested that the loss of pathogenicity was not due to the defects in virulence, but most likely due to failure in appressorial penetration. Similar results have been reported in $M$. grisea PKA mutants. These PKA mutants rarely infected intact rice leaves, but were able to grow and cause lesions when wounding occurred (Xu et al. 1997). For M. grisea, it appears that high concentrations of glycerol are important for the generation of turgor pressure required for mechanical penetration by appressoria (Howard et al. 1991; de Jong et al. 1997). In C. trifolii, it is unknown precisely how penetration occurs, but both mechanical force and enzymatic degradation have been suggested to be involved during this process (Bailey et al. 1992). It is reasonable to hypothesize that PKA may affect pathways resulting in the induction of extracellular cuticle-degrading enzymes, as well as the mobilization of carbohydrate reserves to generate mechanical forces for appressorial penetration. As a considerable degree of identity was found between Ct-PKAC protein and the PKA C subunit of $M$. grisea, including the divergent $\mathrm{N}$ terminus, coupled with the fact that both fungi form appressoria, it is possible that similar mechanisms of mechanical penetration may be operative.

To our knowledge, this is the first report of successful gene replacement in $C$. trifolii. The generation of $C t-P K A C$ replacement mutants indicated that this fungus is amenable to targeted gene disruption, and the methodology used will be important as a framework to be applied in the characterization of other genes cloned in $C$. trifolii, particularly genes required for/during pathogenic development.

\section{MATERIALS AND METHODS}

\section{Strains and media.}

Escherichia coli strain DH5 $\alpha$ (GIBCO BRL, Gaithersburg, MD) was used for the propagation of plasmid DNA. Phagemid vector pBlueScriptKS ${ }^{-}$(Stratagene, La Jolla, CA) was used for the cloning of DNA fragments. E. coli strain Y1090 was used for the amplification of $\lambda$ gt11 phage particles (Stratagene). E. coli strains were cultured in Luria-Bertani (LB) or $2 \times$ YT media with $50 \mu \mathrm{g}$ of carbencillin per $\mathrm{ml}$ when required (Sambrook et al. 1989).

The wild-type strain of Colletotrichum trifolii race 1 used throughout this study was ATCC66954 (Dickman 1988). Both the wild type and the PKA mutants were maintained on YPSS agar plates (Tuite 1969). Conidia, germinating conidia, vegetatively grown mycelia, and mature appressoria were collected as described (Yang and Dickman 1997). For the collection of germinated conidia at 1-h intervals, conidia from 7- to 10-dayold cultures (shaking at $100 \mathrm{rpm}$ at ambient temperature; LabLine Orbit Shaker, Fisher, Pittsburgh, PA) were collected by centrifugation, washed, and resuspended in sterile, distilled water $\left(10^{6}\right.$ conidia per $\left.\mathrm{ml}\right)$. Conidial germination was induced by plating $5 \mathrm{ml}$ of the diluted conidial suspensions in $90-\mathrm{mm}$ glass petri dishes (VWR, Chicago, IL); cells were dislodged from the surface of the petri dishes with a rubber policeman and harvested by centrifugation at 1-h intervals. Washed conidia were used as the zero time point sample. Both liquid culture and the induction of conidia germination as well as appressoria formation were performed at ambient temperature with light and dark intervals of $12 \mathrm{~h}$.

\section{Isolating, cloning, and sequencing of $C t$-PKAC.}

Three degenerate primers were designed based on the conserved regions of PKA C subunits: primer 1 was designed on the conserved region of domain VI; primer 2 was designed on the conserved region of domain IX; and primer 3 was designed on the conserved region of domain VIII (Hanks and Quinn 1991). The primer sequences (not including the EcoRI site at the $5^{\prime}$ end and BamHI site at the $3^{\prime}$ end) are as follows: primer 1, Forward 5'AG(G/A)GACCT(G/A/C/T)AA(G/A) $\mathrm{CC}(\mathrm{G} / \mathrm{C}) \mathrm{GAG} 3^{\prime}$ (RDLKPE); primer 2, Reverse 5'AC (C/T/G) $\mathrm{AC}(\mathrm{C} / \mathrm{T} / \mathrm{G} / \mathrm{A}) \mathrm{G}(\mathrm{G} / \mathrm{C}) \mathrm{GACCACCAGATC} 3^{\prime}$ (DWWSLG); primer 3, Reverse 5'CCG CAA(C/G/T)AG(G/C)GTCCA (G/C)GT3' (TWTLCG).

All primers were dissolved in DEPC (diethylpyrocarbonate)-treated water and diluted to $100 \mathrm{ng} / \mu \mathrm{l} ; 1 \mu \mathrm{l}$ of each primer was used in the 50- $\mu$ PCRs. Other components in the $50-\mu l$ mixture included $200 \mathrm{ng}$ of $C$. trifolii genomic DNA, 0.4 $\mathrm{mM}$ dNTP, $1.5 \mathrm{mM} \mathrm{MgCl}_{2}, 2.5 \mathrm{U}$ of Taq polymerase and $1 \times$ PCR buffer (GIBCO BRL). The PCR was initiated by denaturation at $94^{\circ} \mathrm{C}$ for $5 \mathrm{~min}$, followed by 30 cycles at $94^{\circ} \mathrm{C}$ for 30 $\mathrm{s}, 55^{\circ} \mathrm{C}$ for $15 \mathrm{~s}, 72^{\circ} \mathrm{C}$ for $30 \mathrm{~s}$. After cycling, the reactions were extended at $72^{\circ} \mathrm{C}$ for $10 \mathrm{~min}$ and cooled to $4^{\circ} \mathrm{C}$. PCR fragments were purified by gel electrophoresis, cloned into the pBlueScript $\mathrm{KS}^{-}$plasmid, and sequenced. A PCR-labeled probe was used to screen a $C$. trifolii cDNA library (Buhr et al. 1996). cDNA fragments were released from the phage DNA by digestion with NotI and cloned into the Not I site of $\mathrm{KS}$-plasmid vector. The resulting plasmids were designated $\mathrm{p} C t-P K A C 1$ (the full-length cDNA) and pCt-PKAC2 (the truncated cDNA). The two plasmid clones were mapped, sub- 
cloned, and sequenced on both strands by the dideoxy chain termination method (Sanger et al. 1977).

\section{Manipulation of DNA and RNA.}

C. trifolii genomic DNA was isolated as described (Panaccione et al. 1988). Total RNA was isolated from conidia, germinating conidia, vegetatively grown mycelia, and mature appressoria in TriZOL solution (GIBCO-BRL). The amount of fungal tissue used before grinding in liquid nitrogen was about one-tenth of the TriZOL volume (fresh weight was not measured). Genomic DNA and total RNA from Schizosaccharomyces pombe were isolated according to Rose et al. (1990). Phage DNA and minipreps of plasmid DNA were prepared by standard methods (Sambrook et al. 1989). Commercially available columns (The Nest Group, Southboro, MA) were used for large-scale preparation of plasmid DNA. Restriction-enzyme-digested $C$. trifolii genomic DNA $(2.5 \mu \mathrm{g}$ per lane) was separated on $0.8 \%$ agarose gel in $0.5 \times$ Tris-borateEDTA (TBE) buffer and transferred to charged nylon membrane (MSI, Westborough, MA). Total RNA (15 $\mu$ g per lane) was separated on formaldehyde denatured gels $(1 \%)$ in $1 \times$ morpholinepropanesulfonic acid (MOPS) buffer and transferred to charged nylon membrane (Sambrook et al. 1989). DNA and RNA blots were hybridized in 7\% sodium dodecyl sulfate (SDS), $0.5 \mathrm{M} \mathrm{Na}_{2} \mathrm{HPO}_{4}(\mathrm{pH}=7.2)$, and 2 mM EDTA. For high stringency hybridization, the filters were hybridized at $65^{\circ} \mathrm{C}$ overnight, washed at the same temperature in $2 \times$ SSPE ( $1 \times$ SSPE is $0.18 \mathrm{M} \mathrm{NaCl}$ plus $0.015 \mathrm{M}$ sodium citrate), $0.1 \%$ SDS for $30 \mathrm{~min}$, twice; in $0.1 \times$ SSPE, $0.1 \%$ SDS for 30 min, twice. For low stringency hybridization, the filters were hybridized at $60^{\circ} \mathrm{C}$ overnight, washed with $2 \times$ SSPE, $0.1 \%$ SDS for $20 \mathrm{~min}$ at room temperature once, and washed in the same solution at $60^{\circ} \mathrm{C}$ for $10 \mathrm{~min}$, twice. The washed blots were exposed to Kodak films for various times at $-80^{\circ} \mathrm{C}$.

\section{Transformation-mediated gene replacement.}

A gene replacement vector was constructed in $\mathrm{pCt}-P K A C 1$. The recombinant plasmid was digested with $B g l \mathrm{II}$ at $1,650 \mathrm{bp}$ from the $5^{\prime}$ end, and the cohesive ends were filled in with Klenow (New England Biolabs, Beverly, MA). A HindIII$\mathrm{XbaI}$ fragment $(2.1 \mathrm{~kb})$ from plasmid pHA1.3 (Powell and Kistler 1990) containing an $h p h$ gene expression cassette was filled in with Klenow, and ligated to the above-treated vector (Fig. 3). A 4.6-kb NotI fragment containing the disrupted gene was excised from the final construct, purified by gel electrophoresis, and used to transform protoplasts of the wild-type $C$. trifolii strain. Protoplasts were generated from mycelia grown in stationary culture in YPSS liquid media for 5 to 7 days. Mycelia were collected by filtering the culture through four layers of sterile cheesecloth and digested with Lysing Enzyme (Sigma, St. Louis, MO) solution (5 mg of Lysing Enzyme per $\mathrm{ml}$ in $0.8 \mathrm{M} \mathrm{MgSO}_{4}, 0.2 \mathrm{M}$ sodium citrate, $\mathrm{pH}=6.1$; Kohn et al. 1991). The fungal suspension was incubated at ambient temperature for 1 to $3 \mathrm{~h}$ with shaking (100 rpm; Lab-Line Orbit Shaker, Fisher, Pittsburgh, PA), and was frequently observed under a light microscope to assess the extent of protoplast production. The protoplasts were filtered through sterile glass wool, washed with 1.5 volumes of $0.6 \mathrm{M} \mathrm{KCl}$ through the filter, and centrifuged at 5,000 $\times g$ in a JA-20 rotor (Beckman, Palo Alto, CA) for $20 \mathrm{~min}$ at $4^{\circ} \mathrm{C}$ without braking. The pellet was resuspended in STC solution (1.2 M sorbitol,
$50 \mathrm{mM} \mathrm{CaCl} 2,50 \mathrm{mM}$ Tris- $\mathrm{HCl}, \mathrm{pH}=8.0$ ), washed three times in STC with centrifugation at 2,000 rpm (JA-20 rotor; Beckman, Palo Alto, CA) for 2 min each time, and diluted with STC to a final concentration of $10^{7}$ protoplasts per $\mathrm{ml}$. Linearized DNA ( 1 to $5 \mu \mathrm{g}$ ) in $10 \mu$ of Tris-EDTA (TE) buffer ( $\mathrm{pH}=7.6$ ) was added to $200 \mu \mathrm{l}$ of diluted (as above) protoplast solution. After incubation on ice for $30 \mathrm{~min}, 200 \mu \mathrm{l}$ of $40 \%$ PEG (polyethylene glycol; MW 4,000) in STC was added and the protoplasts were incubated at ambient temperature for $20 \mathrm{~min}$. The transformation mixture (50 to $100 \mu \mathrm{l})$ was spread onto regeneration plates $(0.5 \%$ yeast extract, 0.7 M sucrose, 2\% agar; Difco, Detroit, MI). The plates were sealed with Parafilm and incubated upside down at ambient temperature. Selection medium containing $150 \mu \mathrm{g}$ of hygromycin B per $\mathrm{ml}$ (final concentration) in $0.5 \%$ yeast extract, 0.7 $\mathrm{M}$ sucrose, $0.7 \%$ agar was added $24 \mathrm{~h}$ after regeneration. After 7 to 10 days, putative transformants were transferred to YPSS agar containing $150 \mu \mathrm{g}$ of hygromycin B per $\mathrm{ml}$ and purified by two rounds of single conidial isolation. Initial identification of the gene replacement mutants was performed by PCR. For PCR, two primers flanking the insertion site of the $h p h$ gene expression cassette were designed. Genomic DNA was isolated from single conidial colonies in LETS buffer (Panaccione et al. 1988). PCR cycling conditions were similar to those described previously with an increase in annealing temperature from 55 to $65^{\circ} \mathrm{C}$. The PCR results were confirmed by Southern blot analysis.

\section{Phenotypic characterization of the disruption mutants.}

Gene replacement mutants were characterized by growth rates, conidiation patterns, and pathogenicity on either detached leaves or intact host plants. The growth rate was compared by measuring the diameters of the colonies on rich and minimal media by inoculation with $2-\mathrm{mm}^{2}$ mycelia plugs obtained from the edges of 1-week-old cultures. A 2- $\mu$ l droplet of $10^{5}$ conidia per $\mathrm{ml}$ suspension was spread on plates with either YPSS agar or $1.5 \%$ water agar, and conidiation by the single conidial-originated colony was observed under a light microscope. To evaluate pathogenicity, conidia were harvested from 7-day-old liquid culture, washed twice in sterile, deionized, distilled water and diluted in sterile, deionized, distilled water containing $0.1 \%$ Tween 20 to a final concentration of 5 $\times 10^{5}$ conidia per $\mathrm{ml}$. Detached leaves were inoculated by dropping $2 \mu \mathrm{l}$ of the solution onto the upper surface of 1month-old alfalfa leaves. Whole plants were inoculated by spraying until run-off. After inoculation, the detached leaves were incubated in sealed plates; the entire plants (in tubs) were covered with plastic wrap to maintain high humidity. For inoculation of wounded plants, detached leaves were wounded by blunt-ended forceps and inoculated similarly. Alfalfa cultivars Saranac and Arc (Ostazeski et al. 1979) were used to examine the pathogenicity of various $C$. trifolii strains.

\section{PKA activity assay.}

The assay for PKA activity was performed basically as described (Yang and Dickman 1997). Briefly, conidia (1 to 2 days old) harvested from 7-day-old YPSS liquid culture from the wild-type strain and the disruption mutant M8 were ground in liquid nitrogen with protein extraction buffer $(5 \mathrm{mM}$ EDTA, $50 \mathrm{mM}$ Tris, $\mathrm{pH}$ 7.5) containing protease inhibitors aprotinin $(25 \mu \mathrm{g} / \mathrm{ml})$ and phenylmethyl-sulfonyl fluoride 
(PMSF; $1 \mathrm{mM}$ ). After centrifugation at $12,000 \times g$ at $4^{\circ} \mathrm{C}$ for 20 min (JA-20 rotor; Beckman), the supernatant was collected and used to determine protein concentration (Bradford 1976), which was later diluted to $1 \mu \mathrm{g} / \mu \mathrm{l}$ in the protein extraction buffer containing the protease inhibitors. The following assay for PKA activity level and the calculation of the result were performed according to the manufacturer's instructions (GIBCO BRL). Briefly, protein extracts $(10 \mu \mathrm{l}$ for each treatment) were added to tubes containing $50 \mathrm{mM}$ Tris, $\mathrm{pH} 7.5,10$ $\mathrm{mM} \mathrm{MgCl}, 2.25 \mathrm{mg}$ of bovine serum albumin per $\mathrm{ml}, 100 \mu \mathrm{M}$ $\left[\gamma^{32} \mathrm{P}\right] \mathrm{ATP}$, and $50 \mu \mathrm{M}$ kemptide (model substrate), and incubated at $30^{\circ} \mathrm{C}$ for $5 \mathrm{~min}$. Twenty microliters from each treatment was spotted onto a phosphocellulose disk, acid washed three times ( 5 min each time at room temperature with gentle shaking), and rinsed with water three times. Disks were then counted in a liquid scintillation counter. PKA activity levels from the wild-type strain and from the mutant were calculated according to the manufacturer's instructions and as described in Yang and Dickman (1997).

\section{ACKNOWLEDGMENTS}

We thank Cindy Stryker for technical assistance. This research is supported by the United States-Israel Binational Agricultural Research and Development fund (BARD) (no. US-2814-96) and by the DOE/NSF/ USDA program of Collaborative Research in Plant Biology (no. 9237310-7821). We thank the Center for Biotechnology at the University of Nebraska-Lincoln Sequencing Lab.

\section{LITERATURE CITED}

Bailey, J. A., O'Connell, R. J., Pring, R. J., and Nash, C. 1992. Infection strategies of Colletotrichum species. Pages 88-120 in: Colletotrichum: Biology, Pathology and Control. J. A. Bailey and M. J. Jeger, eds. CAB Int., Oxon, UK.

Barnes, D. K., Ostazeski, S. A., Schillinger, J. A., and Hanson, C. H. 1969. Effects of anthracnose (Colletotrichum trifolii) infection on yield, stand, and vigor of alfalfa. Crop Sci. 9:344-346.

Baroni, M. D., Monti, P., and Alberghina, L. 1994. Repression of growth-regulated G1 cyclin expression by cyclic AMP in budding yeast. Nature 371:339-342.

Bencina, M., Panneman, H., Ruijter, G. J. G., Legisa, M., and Visser, J. 1997. Characterization and overexpression of the Aspergillus niger gene encoding the cAMP-dependent protein kinase catalytic subunit. Microbiology 143:1211-1220.

Bradford, M. M. 1976. A rapid and sensitive method for the quantitation of microgram quantities of protein utilizing the principle of protein dye binding. Anal. Biochem. 22:248-254.

Buhr, T. L., Oved, S., Truesdell, G. M., Huang, C., Yarden, O., and Dickman, M. B. 1996. A kinase-encoding gene from Colletotrichum trifolii complements a colonial growth mutant of Neurospora crassa. Mol. Gen. Genet. 251:565-572.

Churchill, A., Baker, C., O’Neill, N., and Elgin, J. 1988. Development of Colletotrichum trifolii race 1 and 2 on alfalfa clones resistant and susceptible to anthracnose. Can. J. Bot. 66:75-81.

de Jong, J. C., McCormack, B. J., Smirnoff, N., and Talbot, N. J. 1997. Glycerol generates turgor in rice blast. Nature 389:244-245.

Dickman, M. B. 1988. Whole cell transformation of the alfalfa fungal pathogen Colletotrichum trifolii. Curr. Genet. 14:241-246.

Dickman, M. B., Buhr, T. L., Truesdell, G. M., Warwar, V., and Huang, C. 1995. Molecular analysis during the early stages of alfalfa anthracnose. Can. J. Bot. 73(suppl. 1):1169-1177.

Emili, A., Greenblatt, J., and Ingles, C. J. 1994. Species-specific interaction of the glutamine-rich domain of Sp1 with the TATA-box binding protein. Mol. Cell Biol. 14:1582-1593.

Gao, S., and Nuss, N. L. 1996. Distinct roles for two G protein $\alpha$ subunits in fungal virulence, morphology, and reproduction revealed by targeted gene disruption. Proc. Natl. Acad. Sci. USA 93:1412214127.
Gerber, H. P., Seipel, K., Georgiev, O., Hofferer, M., Hug, M., Rusconi, S., and Schaffner, W. 1994. Transcriptional activation modulated by homopolymeric glutamine and poline stretches. Science 263:808-811.

Gold, S. E., Brogdon, S. M., Mayorga, M. E., and Kronstad, J. W. 1997. The Ustilago maydis regulatory subunit of a cAMP-dependent protein kinase is required for gall formation in maize. Plant Cell 9:1581-1594.

Gold, S. E., Duncan, G. A., Barrett, K. J., and Kronstad, J.W. 1994 cAMP regulates morphogenesis in the fungus Ustilago maydis. Genes Dev. 8:2805-2816.

Gross, R. E., Bagchi, S., Lu, X., and Rubin, C. S. 1990. Cloning, characterization, and expression of the gene for the catalytic subunit of cAMP-dependent protein kinase in Caenorhabditis elegans. J. Biol. Chem. 265:3293-3303.

Hanks. S. K., and Quinn, A.M. 1991. Protein kinase catalytic domain sequence database: Identification of conserved features of primary structure and classification of family members. Methods Enzymol. 200:38-62

Hicks, T. K., Yu, J. H., Kelly, N. P., and Adams, T. H. 1997. Aspergillus sporulation and mycotoxin production both requires inactivation of the FadA G $\alpha$ protein-dependent signaling pathway. EMBO J. 16: 4916-4923

Howard, R. J., Ferrari, M. A., Roach, D. H., and Money, N. P. 1991. Penetration of hard substrates by a fungus employing enormous turgor pressures. Proc. Natl. Acad. Sci. USA 88:11281-11284.

Jin, M., Fujita, M., Culley, B. M., Apolinario, E., Yamamoto, M., Maundrell, K., and Huffman, C. S. 1995. Sck1, a high copy number suppressor of defects in the cAMP-dependent protein b kinase pathway in fission yeast, encodes a protein homologous to the Saccharomyces cerevisiae SCH9 kinase. Genetics 140:457-467.

Johnson, L. N., Noble, M. E. M., and Owen, D. J. 1996. Active and inactive protein kinases: Structural basis for regulation. Cell 85:149158.

Knighton, D. R., Zheng, J., TenEyck, L. F., Ashford, V. A., Xuong, N.H., Taylor, S. S., and Sowadski, T. M. 1991. Crystal structure of the catalytic subunit of cyclic adenosine monophosphate-dependent protein kinase. Science 253:414-420.

Kohn, L. M., Stasovski, E., Carbone, I., Royer, J., and Anderson, J. B. 1991. Mycelial incompatibility and molecular markers identify genetic variability in field populations of Sclerotinia sclerotiorum. Phytopathology 81:480-485.

Kronstad, J. W. 1997. Virulence and cAMP in smuts, blasts and blights. Trends Plant Sci. 2:193-199.

Kubo, Y., Suzuki, K., Furusawa, I., Ishida, N., and Yamamoto, M. 1981. Relation of appressorium pigmentation and penetration of nitrocellulose membranes by Colletotrichum lagnarium. Phytopathology 72: 498-501.

Lee, N. N., and Adams, T. H. 1996. FluG and flb A function interdependently to initiate conidiophore development in Aspergillus nidulans through brla $\beta$ activation. EMBO J. 15:299-309.

Lu, X., Gross, R. E., Bagchi, S., and Rubin, C. S. 1990. Cloning, structure, and expression of the gene for a novel regulatory subunit of cAMP-dependent protein kinase in Caenorhabditis elegans. J. Biol. Chem. 265:3293-3303.

Maeda, T., Watanabe, Y., Kunitomo, H., and Yamamoto, M. 1994. Cloning of the pka1 gene encoding the catalytic subunit of the cAMPdependent protein kinase in Schizosaccharomyces pombe. J. Biol. Chem. 269:9632-9637.

Marques, M. V., Borges, A. C. C., Oliveira, J. C. F., and Gomes, S. L. 1992. Coordinate pretranslational control of cAMP-dependent protein kinase subunit expression during development in the water mold Blastocladiella emersonii. Dev. Biol. 149:432-439.

Mitchell, T. K., and Dean, R. A. 1995. The cAMP-dependent protein kinase catalytic subunit is required for appressorium formation and pathogenesis by the rice blast pathogen Magnaporthe grisea. Plant Cell 7:1869-1878.

Mould, M. J., Boland, G. J., and Robb, J. 1991a. Ultrastructure of the Colletotrichum trifolii - Medicago sativa pathosystem I. Pre-penetration events. Physiol. Mol. Plant Pathol. 38:179-194.

Mould, M. J., Boland, G. J., and Robb, J. 1991b. Ultrastructure of the Colletotrichum trifoli $i$ - Medicago sativa pathosystem II. Post-penetration events. Physiol. Mol. Plant Pathol. 38:195-210.

Oliveira, J. C. F., Borges, A. C. C., Marques, M. V., and Gomes, S. L. 1994. Cloning and characterization of the gene for the catalytic subunit of cAMP-dependent protein kinase in the aquatic fungus 
Blastocladiella emersonii. Eur. J. Biochem. 219: 555-562.

Oliveira, J. C. F., Marques, M. V., and Gomes, S. L. 1997. Protein factors in Blastocladiella emersonii cell extracts recognize similar sequence elements in the promoters of the genes encoding cAMPdependent protein kinase subunits. Mol. Gen. Genet. 255:495-503.

Ostazeski, S. A., Elgin, J. H., and McMurtrey, J. E. 1979. Occurrence of anthracnose on formerly anthracnose-resistant Arc alfalfa. Plant Dis. Rep. 63:734-736.

Panaccione, D. G., McKiernan, M., and Hanau, R. M. 1988. Colletotrichum graminicola transformed with homologous and heterologous benomyl-resistant genes retains expected pathogenicity to corn. Mol. Plant-Microbe Interact. 1:113-120.

Perpetua, N. S., Kubo, Y., Okuno, T., and Furusawa, I. 1994. Restoration of pathogenicity of a penetration-deficient mutant of Colletotrichum lagenarium by DNA complementation. Curr. Genet. 25:41-46.

Powell, W. A., and Kistler, H. C. 1990. In vivo rearrangement of foreign DNA by Fusarium oxysporum produces linear self-replicating plasmids. J. Bacteriol. 172:3163-3171.

Rose, M. D., Winston, F., and Hieter, P. 1990. Methods in Yeast Genetics: A Laboratory Course Manual. Cold Spring Harbor Laboratory, Cold Spring Harbor, NY.

Sambrook, J., Fritsch, E. F., and Maniatis, T. A. 1989. Molecular Cloning: A Laboratory Manual. 2nd ed. Cold Spring Harbor Laboratory, Cold Spring Harbor, NY.

Sanger, F., Nicklen, S., and Coulson, A. R. 1977. DNA sequencing with chain terminating inhibitors. Proc. Natl. Acad. Sci. USA 74:5463-5467.

Shoji, S., Ericsson, L. H., Walsh, K. A., Fisher, E. H., and Titani, K. 1983. Amino acid sequence of the catalytic subunit of bovine type II cyclic $3^{\prime}, 5^{\prime}$-phosphate dependent protein kinase. Biochemistry 22 : 3702-3709.

Showers, M. O., and Maurer, R. A. 1986. A cloned bovine cDNA encodes an alternative form of the catalytic subunit of cAMP-dependent protein kinase. J. Biol. Chem. 261:16288-16291.

Stephensen, S.-A., Green, J. R., Manners, J. M., and Maclean, D. J. 1997. Cloning and characterization of glutamine synthetase gene from Colletotrichum gloeosporioides and demonstration of elevated expression during pathogenesis on Stylosanthes guianensis. Curr. Genet. 31:447-454.
Tanaka, M., Clouston, W. M., and Herr, W. 1994. The oct-2 glutaminerich and proline-rich activation domains can synergize with each other or duplicate of themselves to activate transcription. Mol. Cell Biol. 14:6046-6055.

Taylor, S. S., Buechler, J. A., and Yonemoto, W. 1990. cAMP-dependent protein kinase: Framework for a diverse family of regulatory enzymes. Annu. Rev. Biochem. 59:971-1005.

Terenzi, H. F., Flawia, M. M., Tellez-Inon, M. T., and Torres, H. N. 1976. Control of Neurospora crassa morphology by cyclic adenosine 3': 5'-monophosphate and dibutyryl cyclic adenosine $3^{\prime}$ : 5'-monophosphate. J. Bacteriol. 126:91-99.

Toda, T., Cameron, S., Sass, P., Zoller, M., and Wigler, M. 1987. Three different genes in $S$. cerevisiae encode the catalytic subunits of the cAMP-dependent protein kinase. Cell 50:277-287.

Tokiwa, G., Tyers, M., Vilpe, T., and Futcher, B. 1994. Inhibition of G1 cyclin activity by the Ras/cAMP pathway in yeast. Nature 371:342345

Tuite, J. 1969. Plant Pathological Methods. Burgess Pub., Minneapolis. p. 30 .

Uhler, M. D., Chrivia, J. C., and McKnight, G. S. 1986. Evidence for a second isoform of the catalytic subunit of cAMP-dependent protein kinase. J. Biol. Chem. 261:15360-15361.

Walsh, D. A., Perkins, J. P., and Krebs, E. G. 1968. An adenosine 3', 5'monophosphate-dependent protein kinase from rabbit skeletal muscle. J. Biol. Chem. 243:3763-3774.

Wolkow, P. M., Sisler, H. D., and Vigil, E. L. 1983. Effects of inhibitors of melanin biosynthesis on structure and function of appressoria of Colletotrichum lindemuthianum. Physiol. Plant Pathol. 22:55-71.

Xu, J.-R., Urban, M., Sweigard, J. A., and Hamer, J. E. 1997. The CPKA gene of Magnaporthe grisea is essential for appressorial penetration. Mol. Plant-Microbe Interact. 10:187-194.

Yang, Z., and Dickman, M. B. 1997. Regulation of cAMP and cAMP dependent protein kinase during conidial germination and appressorial formation in Colletotrichum trifolii. Physiol. Mol. Plant Pathol. 50:117-127.

Yu, J.-H., Wieser, J., and Adams, T. H. 1996. The Aspergillus FLBA RGS domain protein antagonizes G-protein signaling to block proliferation and allow development. EMBO J. 15:5184-5190. 